Research paper

\title{
Ecology and adaptation of stunted growth in fish
}

\author{
J. YLIKARJULA ${ }^{1,2 *}$, M. HEINO ${ }^{2,3}$ and U. DIECKMANN ${ }^{3}$ \\ ${ }^{1}$ Systems Analysis Laboratory, Helsinki University of Technology, Finland; ${ }^{2}$ Division of Population \\ Biology, Department of Ecology and Systematics, University of Helsinki, Finland; ${ }^{3}$ International \\ Institute for Applied Systems Analysis, Laxenburg, Austria \\ ("author for correspondence, e-mail: janica.ylikarjula@hut.fi; fax: +35894513 096)
}

Received 27 December 1999; accepted 17 April 2000

Co-ordinating editor: H. Kokko

\begin{abstract}
Dwarf individuals are observed in many species of freshwater fish. This paper studies the potential causes of such stunted growth. We present a model which describes the effect of growth conditions on the age- and size-structure of fish populations. The model parameters are chosen to characterize a Eurasian perch population. Two possible causes of stunting are identified: resource limitation and size- or age-dependent survival probabilities. While the former mechanism often arises from intraspecific density dependence, the latter is of particular relevance in the context of interspecific interactions and fishing. After evaluating the immediate ecological consequences of these factors, we examine the potential for life-history adaptations in stunted fish populations. Interactions between the ecological and adaptive mechanisms of stunting are shown to be intricate: not only does the age at maturity of individuals affect their growth trajectories, but, in addition, alterations in growth conditions can result in different adaptively stable ages at maturity. We show that such adaptive responses can either alleviate or amplify stunting caused by ecological factors. Life-history adaptation may also lead to the persistence of stunting when ecological factors alone would allow for normal growth. An appreciation of the interplay between ecological and adaptive factors therefore is critical for understanding the causes and mechanisms of stunted growth.
\end{abstract}

Key words: age-structured population, Eurasian perch, optimal maturity, resource limitation

\section{Introduction}

Stunted growth is a frequently observed phenomenon in freshwater fish populations. In such populations, growth of fish is much diminished relative to the potential of the species (Burrough and Kennedy, 1979) and 'dwarf' individuals are consequently observed. Stunted populations are common, for example, among Arctic charr (Parker and Johnson, 1991), landlocked Atlantic salmon (Leggett and Power, 1969), perch (Rask, 1983; Ridgway and Chapleau, 1994), roach (Burrough and Kennedy, 1979; Linfield, 1980) and lake whitefish (Bodaly et al., 1991). The economic value of stunted fish populations is greatly reduced as most of the potential catch will consist of small fish of little commercial value. Therefore, understanding the ultimate and proximate causes of stunted growth poses an 
important scientific problem, with repercussions both for ecological theory and for fisheries management. Yet, the phenomenon of stunted growth and its potential causes have received only little scientific attention; in particular, theoretical investigations of the mechanisms that can lead to stunting have been scattered (e.g., Diana, 1987; Post and McQueen, 1994; Nibbelink and Carpenter, 1998). Especially studies on the relation between stunting and life-history adaptations have been lacking (however, see Hayes and Taylor, 1990; Beard et al., 1997).

A variety of factors has already been suggested to explain the phenomenon of stunting. These factors include intraspecific competition due to overcrowding (Sandheinrich and Hubert, 1984; Roff, 1992), low food availability (Eschmeyer, 1937; Linfield, 1980; Rask, 1983; Roff, 1992; Post and McQueen, 1994), and increase in survival rate (Roff, 1992). The latter effect can be brought about, for example, by the disappearance of top predators (Grimaldi and Leduc, 1973). Because growth rates in fish rapidly respond to changes in density, they are mainly viewed as plastic phenotypic responses to environmental change, rather than requiring genetic changes for their alteration (Reimers, 1979; Roff, 1992; Linløkken and Seeland, 1996). In addition, yellow perch (Perca flavescens) and pumpkinseed individuals from stunted and non-stunted populations showed no differences in growth after taken to optimal laboratory conditions (Heath and Roff, 1987). This indicates that the differences observed in growth in the field are mostly a result of environmental variation and not of genetic differentiation. The suggested proximate causes for stunting all result in more severe resource limitation. Our hypothesis therefore is that strong resource limitation is the single ultimate cause of stunting. Under conditions of low resource availability, individuals will allocate resources mainly to maintain their biomass. Only small amounts of resources can then be invested into individual growth, resulting in a decrease of annual growth increments.

In addition to these immediate effects, poor growth conditions and severe resource limitation may result in altered life histories of fish populations. Especially the age at maturation is expected to be affected under these circumstances. The age at maturity in stunted populations is observed to be generally lower than or equal to that in normal populations, although differences are often small and contradictory observations exist (Alm, 1959; Roff, 1992). Changes in age at maturity influence post-maturation growth rates and can thus either amplify or alleviate stunting. An analysis of the phenomenon of stunting therefore is incomplete without considering these indirect adaptive responses on top of the more direct ecological effects.

In this study, we focus on the Eurasian perch (Perca fluviatilis L.) to analyze the ecological conditions that are conducive to stunting. Perch is a common fish species in freshwater systems almost all over Europe and in the northern part of Asia. The typical length of adult Eurasian perch is $15-30 \mathrm{~cm}$, and the largest individuals are $40-45 \mathrm{~cm}$ (Koli, 1990). However, if growth rates are 
small, the largest individuals in a population may be no bigger than $16 \mathrm{~cm}$ (Tesch, 1955). Dwarf forms of perch are most often found in small lakes. In such habitats perch is typically the only fish species, or is coexisting together with roach (Koli, 1990; Linløkken and Seeland, 1996).

In this paper we first develop a population dynamical model where resource limitation is taken into account by considering density-dependent growth increments of individual fish (see Modeling techniques). Density-dependent growth has been observed for perch populations (e.g., Rask, 1992). Based on this age-structured model, we demonstrate that a variety of ecological gradients for age- or size-dependent mortality may lead to increasing levels of stunting (see Results). This effect is shown for

1. increased survival of larger fish (corresponding to diminished fishing pressure),

2. increased juvenile and adult survival (corresponding to diminished overall predation pressures or to lower risks of catching parasites or diseases),

3. decreased density dependence in newborn survival (corresponding to diminished predation on newly-hatched fry or to a lower prevalence of egg diseases), and

4. increased survival of smaller fishes (corresponding to diminished predation pressures on smaller size classes).

The last ecological gradient is taken into account because the presence of fish predators is likely to have a much weaker effect on the survival of large perch than on that of small ones: while the latter are susceptible to predators of all sizes, the larger body sizes of adult perch make them less vulnerable to predation (see e.g., Szalai and Dick, 1991). For example, Campbell (1998) showed that the attack and consumption rates of walleyes (Stizostedion vitreum) feeding on yellow perch were significantly greater for small than for intermediate and large prey. The four investigated gradients correspond to the putative explanations that have been put forward for stunting. In addition to the immediate effects of these altered demographic conditions, adaptive responses in the age at maturity and their implications for the size of fish are investigated in detail (see Results). For all four gradients, we evaluate consequences of stunted growth for the total biomass of fish populations.

\section{Modeling techniques}

In this section, we derive an age-structured model in discrete time to capture the typical features of fish populations. In many of these populations, environmental conditions are seasonal, vital rates are age- and/or size-dependent, and growth is indeterminate and slows down after maturation. 


\section{Model description}

The annual cycle of reproduction and overwintering is measured in units of years and indexed by $t$, and the number of individuals in age class $a$ just before reproduction during the season $t$ is denoted by $N_{a}(t)$. The parameter $a_{\mathrm{m}}$ measures the age at maturity and $a_{\max }$ is the maximum feasible age, $a=0,1, \ldots, a_{\mathrm{m}}, \ldots, a_{\max }$. All individuals within each age class are assumed to be equivalent. The total abundance at time $t$ is obtained by summing abundances over all age classes,

$$
N_{\text {tot }}(t)=\sum_{a=1}^{a_{\max }} N_{a}(t) .
$$

\section{Reproduction and survival}

The number of offspring produced by an individual in age class $a$ is $f_{a}$ so that the total amount of offspring born during the reproductive season $t$ is

$$
N_{0}(t)=\sum_{a=a_{\mathrm{m}}}^{a_{\max }} f_{a} N_{a}(t) .
$$

Individuals in age class $a$ survive to the next season with probability $s_{a}$,

$$
N_{a+1}(t+1)=s_{a} N_{a}(t) \quad \text { for } a=0, \ldots, a_{\max }-1 .
$$

\section{Somatic growth}

The growth of individual fish is envisaged in accordance with the energy allocation model by Roff, 1983 (see also Perrin and Rubin, 1990; Heino and Kaitala, 1997). It is assumed that there is a size-dependent amount of surplus energy in excess of maintenance. For immature fish, this surplus energy is devoted to somatic growth, and annual length increments for immature fish are assumed to be independent of age and size, resulting in linear growth trajectories. Upon maturation, a certain proportion of this surplus energy is invested into reproduction instead of growth. Due to resource limitation, there is a clear-cut tradeoff between somatic growth and reproduction - the energy that is consumed for the growth of gonadal tissue diminishes somatic growth and, thus, future reproduction. We assume the ratio between the weight of gonads and somatic weight (the gonadosomatic index $G$ ) to be constant. This assumption has been shown to be valid for perch and a large variety of other fish species (Roff, 1983). Then the length $L_{a+1}$ of fish in age class $a+1$ is given by

$$
L_{a+1}=\left\{\begin{array}{ll}
L_{a}+\Delta\left(L_{a}\right) & \text { for } 0 \leq a<a_{\mathrm{m}}-1 \\
\frac{L_{a}+\Delta\left(L_{a}\right)}{\sqrt[3]{1+G}} & \text { for } a \geq a_{\mathrm{m}}-1
\end{array},\right.
$$


where $\Delta\left(L_{a}\right)$ is the annual maximum somatic length increment for an individual of length $L_{a}$. Since we assume that the somatic increment in each season is age- and size-independent (given by $\Delta$ ), Equations (4) can be rewritten as

$$
L_{a}= \begin{cases}L_{0}+a \Delta & \text { for } 0 \leq a<a_{\mathrm{m}} \\ \frac{L_{0}+\Delta\left(a_{\mathrm{m}}-1+\frac{1-(1+G)^{\left(a-a_{\mathrm{m}}+1\right) / 3}}{1-(1+G)^{1 / 3}}\right)}{(1+G)^{\left(a-a_{\mathrm{m}}+1\right) / 3}} & \text { for } a \geq a_{\mathrm{m}}\end{cases}
$$

where $L_{0}$ is the length at hatching.

Size-dependent fecundity

The weight $W_{a}$ of individual fish at age $a$ (before the reproductive season) is calculated according to

$$
W_{a}=\alpha L_{a}^{3},
$$

with a constant conversion coefficient $\alpha$. Then the increase in body weight in mature fish is

$$
\alpha\left[\frac{\left(L_{a}+\Delta\right)^{3}}{1+G}-L_{a}^{3}\right]
$$

and the excess nutritional resources are

$$
\alpha\left[\left(L_{a}+\Delta\right)^{3}-\frac{\left(L_{a}+\Delta\right)^{3}}{1+G}\right] .
$$

These resources are used for reproduction. Assuming that the weight of one offspring is constant (given by $w_{0}$ ), the number of offspring produced between ages $a$ and $a+1$ and released at age $a+1$ is obtained from Equation (8) by first dividing it by $w_{0}$ and then simplifying that expression. Thus,

$$
f_{a+1}=\frac{\alpha G}{w_{0}(1+G)}\left(L_{a}+\Delta\right)^{3} .
$$

Substituting Equation (5) for the length of mature fish into (9) gives the fecundity at age $a \geq a_{\mathrm{m}}$,

$$
f_{a}=\frac{\alpha G}{w_{0}(1+G)}\left[\frac{L_{0}+\Delta\left(a_{\mathrm{m}}-1+\frac{1-(1+G)^{\left(a-a_{\mathrm{m}}\right) / 3}}{1-(1+G)^{1 / 3}}\right)}{(1+G)^{\left(a-a_{\mathrm{m}}\right) / 3}}+\Delta\right]^{3} .
$$

\section{Biomass}

The biomass of the age class $a$ is the product of the weight $W_{a}$ of an individual fish in age class $a$ and the number of individuals in that same age class, i.e. $W_{a}(t) N_{a}(t)$ for $a=0, \ldots, a_{\max }$. The total biomass at time $t$ is then the sum of biomasses over all age classes: 


$$
W_{\mathrm{tot}}(t)=\sum_{a=1}^{a_{\max }} W_{a}(t) N_{a}(t) .
$$

Density-dependent growth

Variations of growth rates with population density are incorporated into the model by assuming a Beverton-Holt-type functional response (Beverton and Holt, 1957),

$$
F(b, X)=\frac{1}{1+b X},
$$

where $X$ is some measure of population abundance and $b$ is a constant parameter that scales the carrying capacity of the fish stock. Then the annual increment in year $t$, given a total biomass, $W_{\text {tot }}(t)$, and an annual maximum somatic growth increment in the absence of density-dependent growth, $\Delta_{\text {growth }}$, is

$$
\Delta=\Delta_{\text {growth }} F\left(b_{\text {growth }}, W_{\text {tot }}(t)\right) \text {. }
$$

Thus, the greater the biomass is in a given year, the smaller the actual annual growth increment in the length of fish. Equations (3), (10), and (13) thus define the baseline model for stunted growth.

Other density-, age-, or size-dependent factors

To investigate implications of the four ecological gradients described in the Introduction, we consider variations of the baseline model as below. The functional response (12) is also used for modeling density dependence in newborn survival: $s_{0}=s_{\text {newborn }} F\left(b_{\text {newborn }}, N_{0}(t)\right)$, where $s_{\text {newborn }}$ is the probability of a newborn to survive to age 1 in the absence of density dependence. Thus, as the number of newborns increases, their survival probability decreases. For modeling size-dependent survival, either due to fishing pressures or to predation pressures on small size classes, we use the following function:

$$
P\left(m, p, L^{\prime}, L\right)=\max \left(m\left\{1-\exp \left[-p\left(L-L^{\prime}\right)\right]\right\}, 0\right) .
$$

Parameter $L^{\prime}$ characterizes the maximum length for which $P=0, p$ determines the curve's slope at that point, and $m$ gives the maximum value of $P$. Sizedependent juvenile and adult survival for all ages $a \geq 1$ is then described by $s_{\text {fishing }}=1-P\left(m_{\text {fishing }}, p_{\text {fishing }}, L_{\text {fishing }}, L_{a}\right)$ (in the case of fishing pressures, survival is negatively related to the length of the fish) or by $s_{\text {predation }}=$ $P\left(m_{\text {predation }}, p_{\text {predation }}, L_{\text {predation }}, L_{a}\right)$ (in the case of predation pressures, survival is positively related to the length of the fish). A variety of curves of these families, corresponding to different values of parameters $m, p$ and $L^{\prime}$, are shown in Figure 1a, b. 

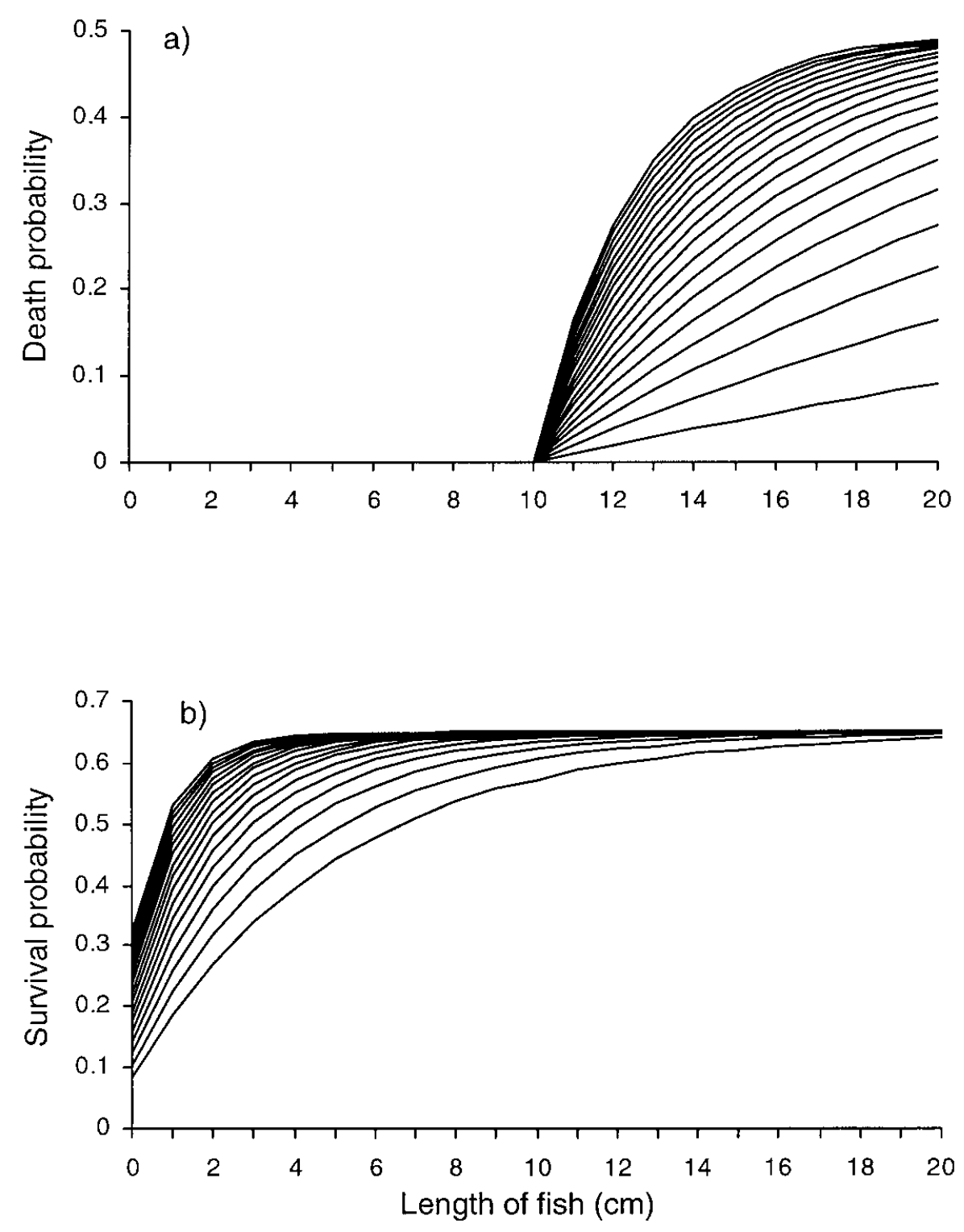

Figure 1. (a) Death probabilities for size-selective fishing (larger fish are harvested more severely). Parameter values: $m_{\text {fishing }}=0.5, p_{\text {fishing }}=0: 0.02: 0.4 \mathrm{~cm}^{-1}$, and $L_{\text {fishing }}=10 \mathrm{~cm}$. (b) Adult survival probabilities for size-selective predation (small fish suffer more). Parameter values: $m_{\text {predation }}=0.65$, $p_{\text {predation }}=0.2: 0.05: 1 \mathrm{~cm}^{-1}$, and $L_{\text {predation }}=-0.7 \mathrm{~cm}$.

\section{Choice of parameter values}

Parameter values for the model are selected to describe Eurasian perch populations. The probability that a perch egg is fertilized and hatches is very high (Nyberg, 1976; Zeh et al., 1989), and the probability that a newly-hatched perch fry survives to age 1 varies between 0.0001 and 0.0015 (Nyberg, 1976). In our model we use the value $s_{\text {newborn }}=0.0012$ for the probability of a newborn to survive to age 1 in the absence of newborn density dependence. Juvenile and adult survival probabilities of perch show strong variations among different 
populations (Alm, 1959; Craig et al., 1979). We use the value $s_{a}=0.7$ for $a \geq 1$, obtained for Lake Horkkajärvi in Finland (Rask, 1983). The maximum annual increase in length is set to $\Delta_{\text {growth }}=4 \mathrm{~cm}$ (Viljanen and Holopainen, 1982), and the parameter for density-dependent growth is $b_{\text {growth }}=10^{-5} \mathrm{~g}^{-1}$. With this value of $b_{\text {growth }}$, the baseline model produces an equilibrium population size of $1.88 \cdot 10^{4}$ individuals. The gonadosomatic index is assumed to be constant, $G=0.1954$, and is calculated from the data given by Treasurer (1981). The value of the conversion coefficient for weight, $\alpha=0.0164 \mathrm{~g} \mathrm{~cm}^{-3}$, is calculated from the same data. In perch, the length of newborns varies between 5.5 and $7.3 \mathrm{~mm}$ (Viljanen and Holopainen, 1982) and we use a value of $L_{0}=6 \mathrm{~mm}$. The weight of a newborn, $w_{0}=0.0035 \mathrm{~g}$, is based on $L_{0}$ and is calculated from Equation (6). The age at maturity of female perch varies between 2 and 4 years (Alm, 1959; Treasurer, 1981; Linløkken and Seeland, 1996) and it can be even higher if growth rates are very poor (Alm, 1959). In the basic case of stunted populations, the age at maturity is assumed to be $a_{\mathrm{m}}=5$ years. In the studies carried out in ponds in Kälarne Fishery Research Station in Sweden (Alm, 1959), the maximum age of perch individuals was 21 years; in our model we set the maximum age of perch to $a_{\max }=20$ years.

\section{Calculation of the adaptively stable age at maturity}

In order to study adaptive responses to changes in growth conditions, we calculate the adaptively stable age at maturity according to the definition of an evolutionarily stable strategy (ESS). The environmental feedback in our model is one-dimensional. Under such conditions, convergence stability (invasion of strategists with small variations in the age at maturity leads to the establishment of strategies in the population that approach the ESS) is implied by evolutionary stability (the ESS itself is resistant to the invasion of varied strategists) (Geritz et al., 1998). Although a one-dimensional environmental feedback results in the existence of an optimization principle (Metz et al., 1996), it is not possible to express the optimized function for our model in a closed form. For this reason, we determine the adaptively stable age at maturity by numerical simulations.

The adaptively stable age at maturity is calculated as follows. First, the resident population (with a given resident age at maturity) is allowed to approach its population dynamical equilibrium for 500 generations. Then, a newborn mutant (with an age at maturity increased or decreased by 1 year relative to the resident) is introduced into the resident population to test whether it can invade and replace the resident strategy. The model is run until the age structure of the population has stabilized and it can be observed whether the size of the mutant population increases or decreases. Invasions are considered to be successful if the mutant increases in abundance. A resident 
strategy that is resistant to invasion by all possible mutant strategies is considered adaptively stable.

Notice that our definition of the adaptively stable age at maturity does not require the existence of genetic change in regard to this strategy. It is possible and, given the time scales involved in adaptation, much more likely - that changes in the age at maturity result from plastic responses to altered environmental conditions. The underlying reaction norm for the age at maturity can then be envisaged as having evolved on a much longer time scale than that on which environmental conditions are changing and adaptive responses occur. However, whether such adaptations in the age at maturity are of plastic or genetic origin is immaterial in our analysis and leaves all the results reported below unaffected.

\section{Results}

Incorporating resource limitation into the model by using a density-dependent annual growth increment has strong effects on growth trajectories. This is illustrated in Figure 2. Without any growth limitation $\left(b_{\text {growth }}=0\right)$, the length of fish in the oldest age class is about $45 \mathrm{~cm}$, close to the maximum size observed in nature. With density dependence in growth $\left(b_{\text {growth }}=10^{-5} \mathrm{~g}^{-1}\right)$, the maximum length is decreased to less than $20 \mathrm{~cm}$, which is in good agreement with values observed in stunted perch populations (Deelder, 1951; Tesch, 1955; Rask, 1983). Also the growth curves of stunted and normal yellow perch populations in Québec (Roff, 1986) are very similar to the ones obtained with our model. Allowing for resource-limited growth is therefore sufficient for explaining stunting.

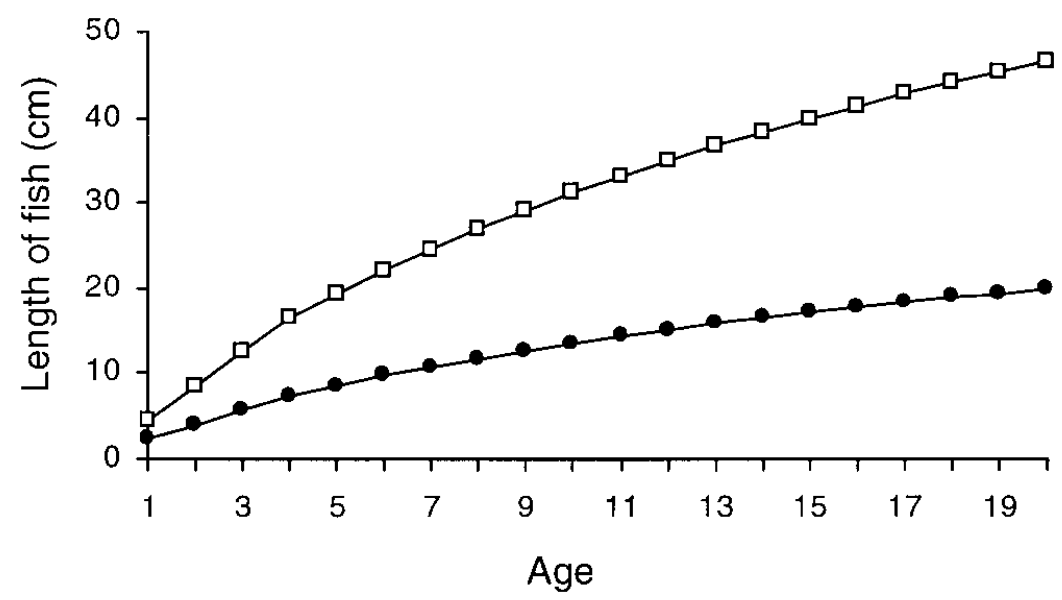

Figure 2. Length of fish at different ages without growth limitation ( $\square$ ) and with density-dependent growth (O). Resource limitation decreases the length of fish considerably. 
Having shown that resource limitation can be the ultimate cause for stunting, we now focus on different proximate causes, all of which can induce situations where resource limitation becomes so strong that stunting is observed. We envisage these effects along four ecological gradients (increased survival of larger fish, increased juvenile and adult survival, decreased density dependence in newborn survival and increased survival of smaller fish), corresponding to the continuous variation of demographic parameters. Scenarios along these gradients can be conceived as being realized either in space or in time. At one end of these gradients, normal growth prevails. Along each gradient, resource limitation becomes increasingly severe, such that at the other end of the gradient growth is retarded and stunting is observed. The ecological gradients we are investigating can all be understood as variations in age- or size-specific survival probabilities. More detailed ecological motivations are given below where we separately focus on different proximate causes of stunted growth. Notice that all the factors studied also affect the abundance and biomass of the fish population. These effects, however, only translate into alterations in growth conditions, and thus in the size of fish, if density dependence in growth is considered.

\section{Survival of larger fish}

We first show that a relaxation of fishing pressure can cause stunting. Fishing mortality is typically strongly size-dependent. This effect is incorporated into the model such that fishery-induced mortality increases with the length of fish (Fig. 1a). The parameter $1-s_{\text {fishing }}$ describes the maximum death probability resulting from fishing. Higher values of the parameter $p_{\text {fishing }}$ correspond to increased harvesting intensities. Only fish larger than $10 \mathrm{~cm}$ are assumed to be vulnerable to fishing gear, i.e. $L_{\text {fishing }}=10 \mathrm{~cm}$.

We first investigate the ecological effects that changes in fishing pressures have on the length of fish and on their total biomass. The age at maturity is assumed to be constant, $a_{\mathrm{m}}=5$. Without fishing, the fish population has a high abundance, resulting in strong competition for resources. Consequently, growth is slow and stunting is observed. Increasing the fishing pressure decreases the strength of resource competition. Stunting vanishes and normalsized fishes are observed (Fig. 3b). This effect is expected because increased levels of fishing mortality decrease the stock's biomass and therefore allow for higher food availability for the surviving fish, resulting in increased length-atage. The figure only depicts the effect on the length of fish in age class 12 because population sizes in older age classes are exceedingly small. Results for all other age classes are qualitatively very similar. The increase in the size of individual fish cannot compensate for the decrease in survival probability; therefore fishing results in a clear decline in total biomass. The slight 

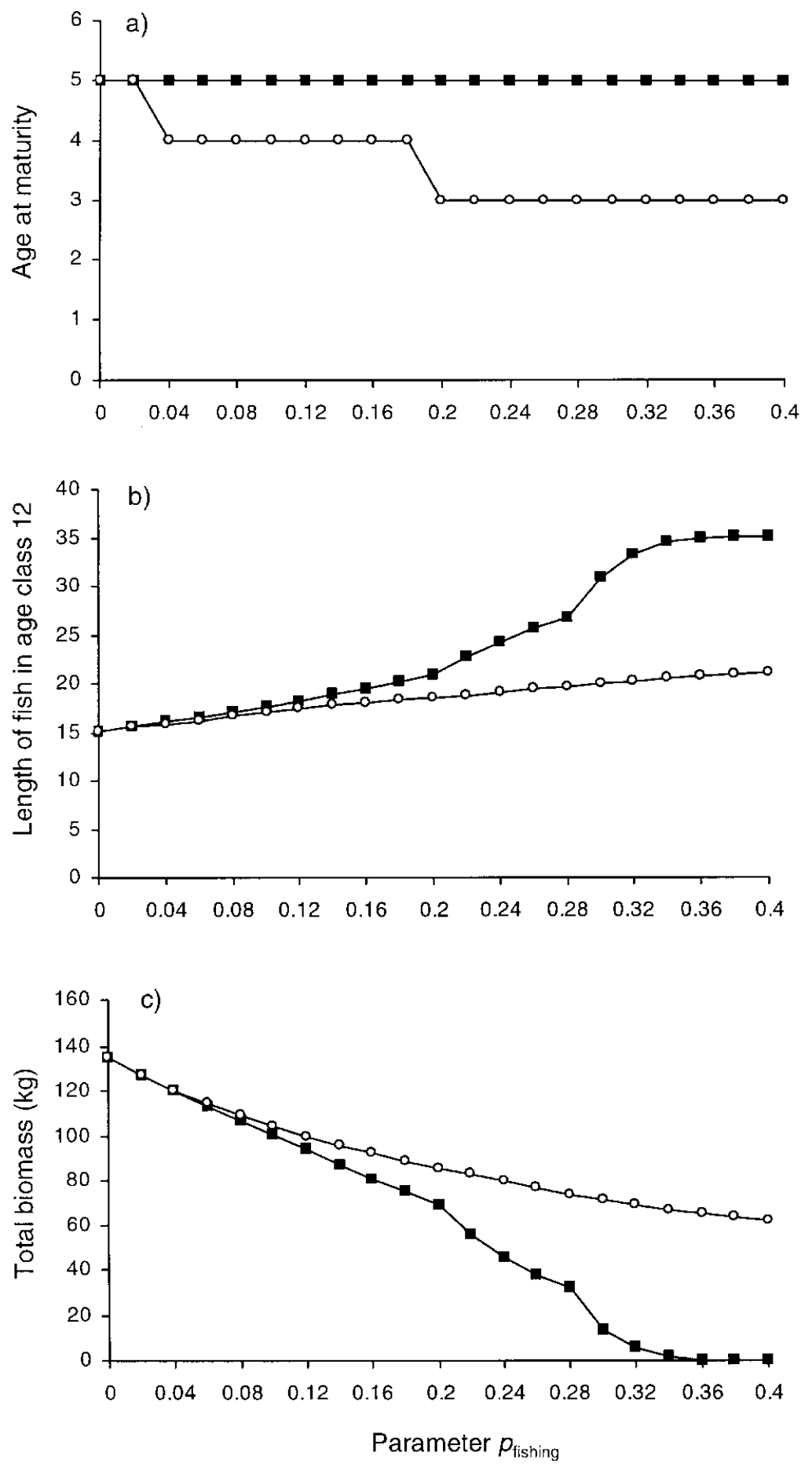

Figure 3. Effects of decreased survival probabilities of larger fish on (a) age at maturity, (b) length of fish in age class 12, and (c) total biomass without adaptation ( $\bullet$ ) and with adaptive responses taken into account $(\bigcirc)$. Parameter values: $m_{\text {fishing }}=0.5, \quad p_{\text {fishing }}=0: 0.02: 0.4 \mathrm{~cm}^{-1}$, and $L_{\text {fishing }}=10 \mathrm{~cm}$.

irregularities in changes of length and biomass are artifactual and originate from the deterministic model formulation: the number of age classes exposed to fishing changes discontinuously as the growth rate increases. 
In a second step, we also want to assess the importance of adaptive responses to fishery-induced changes in growth conditions. We therefore explore adaptively stable ages at maturity for different levels of fishing mortality. As fishing pressure increases, the adaptively stable age at maturation decreases from 5 to 3 years (Fig. 3a). This adaptive response has a marked effect both on length-at-age and on total biomass: earlier maturation slows down postmaturation growth, and this decrease almost compensates for the increased growth rates resulting from more intensive fishing (Fig. 3b). With adaptations in the age at maturity, also the total biomass does not decrease as dramatically with increased fishing mortality as without this adaptive response (Fig. 3c). In summary, phenotypically plastic adaptations can partially compensate for the immediate ecological effects of fishing on growth rates. Ignoring such adaptive responses in a study of stunting can therefore be misleading.

\section{Juvenile and adult survival}

Alterations in predation pressures and in risks of parasitism or disease infection can change the survival probability of juveniles and adults. Increasing juvenile and adult mortality $\left(1-s_{a}\right.$ for $\left.a \geq 1\right)$ dramatically reduces the total biomass; therefore, resource competition is relaxed and growth approaches to normal levels (Fig. 4).

When adaptive responses to decreased juvenile and adult survival are taken into account, the age at maturity decreases, similarly as in the case of fishing, from 5 to 3 years. However, in this case changes in the length of fish and in total biomass resulting from adaptation are minor (Fig. 4). Very similar results are obtained when the juvenile and adult survival probabilities are assumed to be density-dependent: as expected, stunting is observed when the strength of this density dependence decreases.

\section{Density-dependent newborn survival}

Egg diseases and predators preying on newly-hatched fry are factors that may increase the density dependence of newborn mortality. The effects observed for the lengths of fish and for total biomass are similar to those in the previous two cases (Fig. 5). If the maximum annual growth increment is set to $\Delta_{\text {growth }}=4 \mathrm{~cm}$, no adaptive changes in age at maturity are observed in the model. If this increment is increased to $5 \mathrm{~cm}$, an adaptive response occurs and the age at maturity increases to 6 years when density dependence in newborn survival is sufficiently strong. This effect probably occurs because improved growth slightly increases the relative value of reproduction 

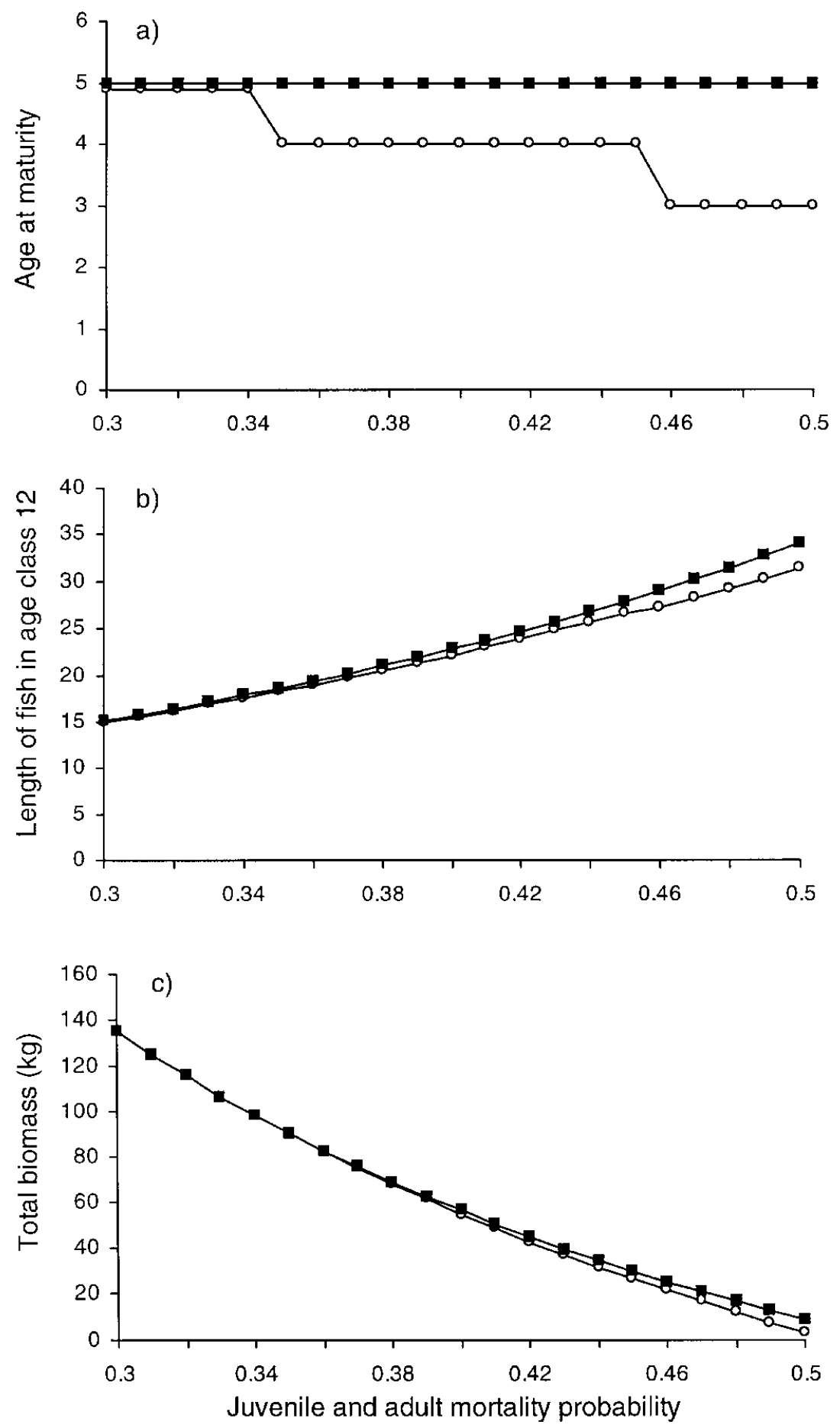

Figure 4. Effects of increased juvenile and adult mortality on (a) age at maturity, (b) length of fish in age class 12, and (c) total biomass without adaptation ( $\mathbf{0})$ and with adaptive responses taken into account $(\bigcirc)$. Parameter values: $1-s_{a}=0.3: 0.01: 0.5$ for $a \geq 1$.

late in life. The increase in the age at maturity amounts to a qualitative difference relative to the previous two cases, where the age at maturity decreased when the length of fish increased. Yet, even for $\Delta_{\text {growth }}=5 \mathrm{~cm}$, changes resulting from adaptive responses in the length of fish and in their 

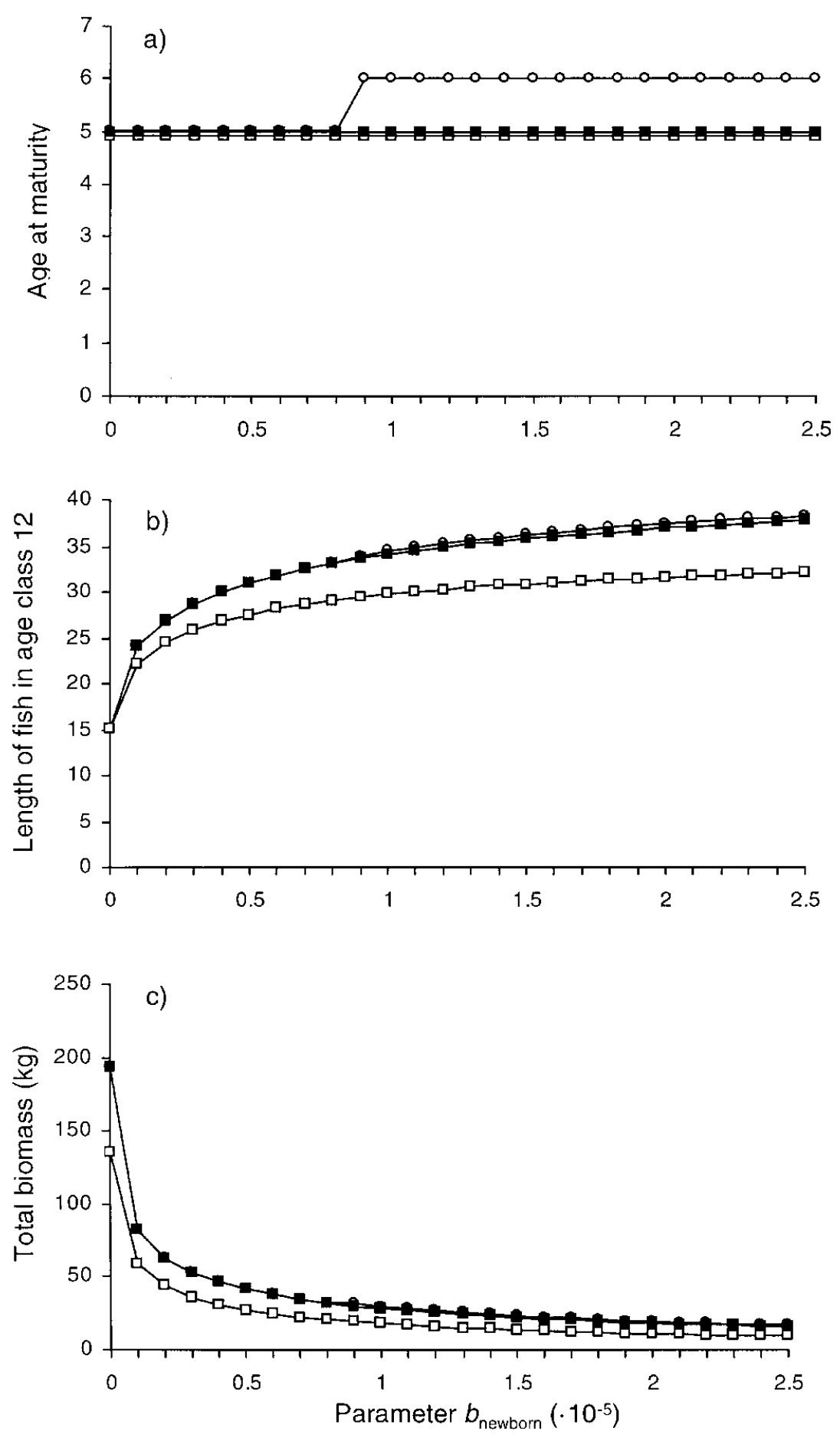

Figure 5. Effects of increased density dependence in newborn survival probabilities on (a) age at maturity, (b) length of fish in age class 12, and (c) total biomass without adaptation ( $\boldsymbol{\square}$ ) and with adaptive responses taken into account $(\bigcirc)$ for $\Delta_{\text {growth }}=5 \mathrm{~cm}$. For $\Delta_{\text {growth }}=4 \mathrm{~cm}(\square)$, there are no effects of adaptation, but for $\Delta_{\text {growth }}=5 \mathrm{~cm}$, adaptive responses have a visible effect. Parameter values: $b_{\text {newborn }}=0: 10^{-6}: 2.5 \cdot 10^{-5} \mathrm{~g}^{-1}$.

biomass are very small. As can be expected, increasing the annual growth increment from 4 to $5 \mathrm{~cm}$ leads to larger lengths-at-age and to an increase in total biomass. 
Survival of small fish

We consider size-dependent survival, as depicted in Figure 1b, to investigate the consequences of changes in survival probabilities of smaller fish. Increasing the mortality of smaller fish leads to larger lengths-at-age and to a decrease in total biomass (Fig. 6). Adaptation to decreasing death rates for smaller fish results in earlier maturation. In its relation to growth rate this adaptive response is qualitatively different from those observed for alterations in sizeindependent survival or for survival probabilities decreasing with size due to fishing. However, the changes in the lengths of fish and in their total biomass resulting from this adaptive response are minor.

\section{Discussion}

In this paper, we have studied possible causes of stunted growth in freshwater fish populations and have investigated the potential for adaptive change resulting from alterations in growth conditions. The analysis presented in this paper demonstrates that incorporating resource limitation into age-structured models (in the form of density-dependent annual growth increments) is sufficient to explain stunted growth. Other conjectured causes of stunting (size- or age-dependent survival probabilities) all result in decreased food availability and can thus be considered as proximate causes of stunting. However, these proximate causes affect growth conditions of the fish only if, in addition, growth is density-dependent.

We have also examined the effects of the four ecological gradients discussed in the previous section in conjunction with a density dependence of Ricker type (Ricker, 1975). Results did not change qualitatively, as long as population dynamics remained stable. Neither did we observe qualitative alterations of our findings when we allowed for a weak density dependence in survival probabilities. We can therefore conclude that the results reported here are not restricted to a certain form of density dependence, nor are they limited to density dependence acting only on specific parts of the life history.

Potential causes of stunted growth are elucidated by some observational evidence. Rask (1983) compared differences in growth conditions in a pair of perch populations living in two small forest lakes in Finland. He suggested that observed differences in growth patterns can be explained by differences in feeding conditions: in the lake with normal-sized perch, predation by pike kept the population density low enough to prevent the population from experiencing severe intraspecific competition for resources. Growth of stunted perch was also studied in Dutch inland waters (Deelder, 1951). Perch growth for this population was observed to be fast during the first years of the study, while 

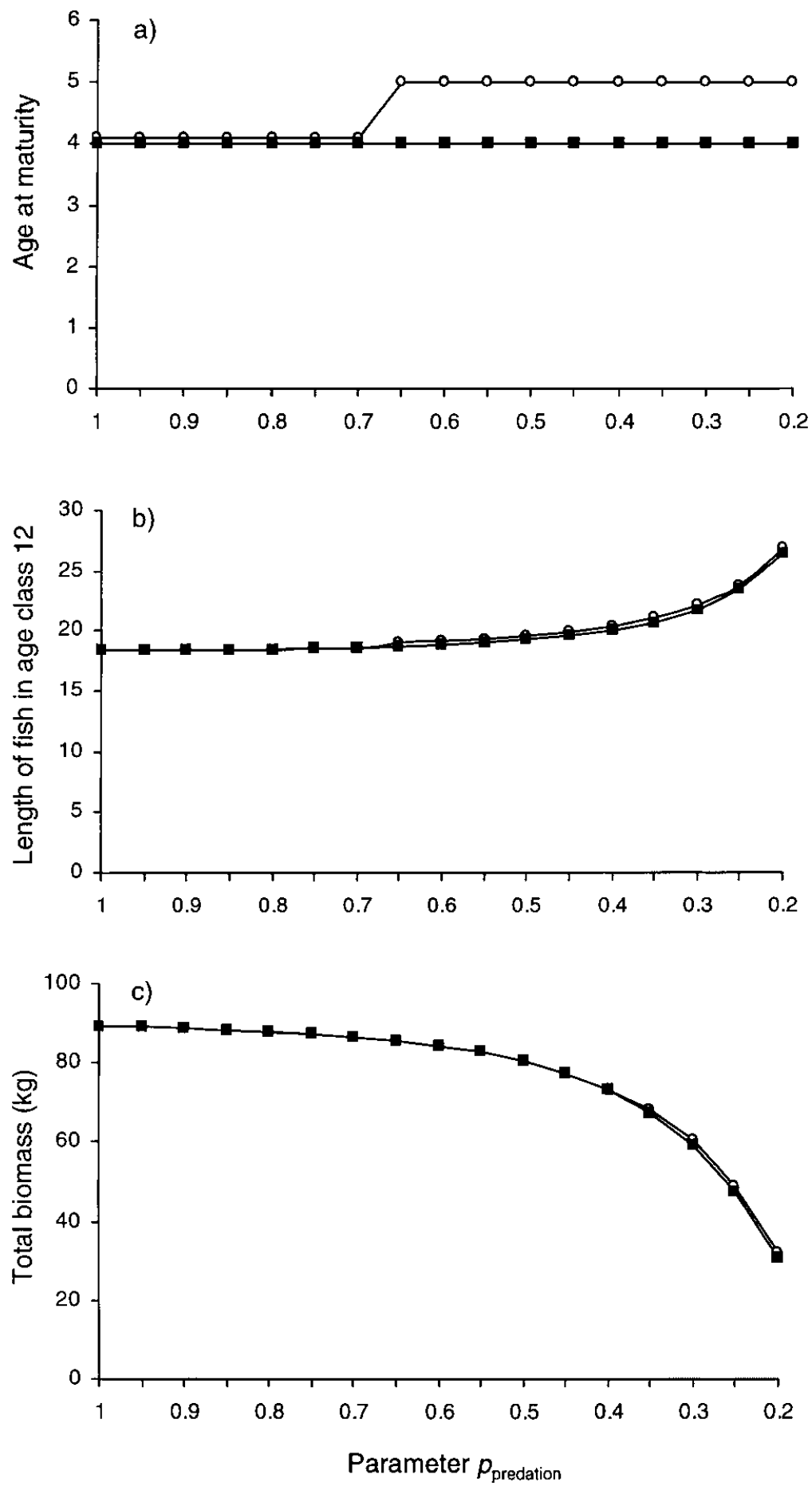

Figure 6. Effects of decreased survival probabilities of smaller fish (increased predation pressures on smaller size classes) on (a) age at maturity, (b) length of fish in age class 12, and (c) total biomass without adaptation $(\boldsymbol{\square})$ and with adaptive responses taken into account $(\bigcirc)$. Parameter values: $m_{\text {predation }}=0.65, p_{\text {predation }}=0.2: 0.05: 1 \mathrm{~cm}^{-1}$, and $L_{\text {predation }}=-0.7 \mathrm{~cm}$.

growth rates dropped to almost zero subsequently. The conjectured origin of this change was a shortage of prey fish, an assertion supported by the fact that growth rates decreased most dramatically for those age groups in which perch individuals gradually switch to a fish diet. Stunted growth of yellow perch has 
also been observed in a lake in Canada. Here stunting was supposed to be caused by overpopulation and strong intraspecific competition, probably resulting from an absence of predators and the lack of adequate prey (Ridgway and Chapleau, 1994).

Alleviation of stunting has been observed in a population of roach (Burrough and Kennedy, 1979). There, high parasite-induced mortalities had increased the growth rate of fishes so that normal-sized individuals could emerge after years of stunted growth. Likewise, average lengths-at-age increased significantly in a previously stunted whitefish population following a period of intensive fishing in Northern Norway (Amundsen, 1988). In South-East Norway, biomass removal of perch has led to increased growth rates (Linløkken and Seeland, 1996). However, assessing the consequences of such biomass removal is not unambiguous since other fish species were removed simultaneously. Moreover, it cannot be excluded that the observed increase in growth rates has resulted from an improvement of water quality.

In this study we have shown that adaptive change in age at maturity is expected in response to changing growth conditions. The nature of the response, however, depends on the specific mechanism that causes the alteration of growth rates: stunting caused by increased survival of larger fish or by increased juvenile and adult survival increases the age at maturity. By contrast, stunting caused by decreased density dependence in newborn survival or by increased survival of smaller fish decreases the age at maturity. The results obtained in this study are in accordance with general predictions from lifehistory theory: reduced adult survival selects for earlier maturation (see Section 'Survival of larger fish'), whereas reduced juvenile survival selects for later maturation (see Section 'Survival of small fish'). These theoretical results are also supported by experimental field evidence (Reznick et al., 1990, Hutchings, 1993).

Under favorable growth conditions, maturity is reached earlier and usually at smaller body sizes than for small growth rates. This is a consequence of accelerated gonad development enabled by high growth rates. Yet, exceptions from this simple relation may be possible: for severely stunted populations the age at maturity can be very low (Alm, 1959). To explain this effect, it has been suggested that lack of food may result in fishes hastening their reproduction 'for the benefit of their species' (Alm, 1959; and references therein). Invocation of such a group selectionist argument, however, is legitimate only if an underlying mechanism can be described at the individual level. Moreover, other experiments at Kälarne Fishery Research Station in Sweden have shown that stunted populations contain no mature females at age 4 or younger and that populations with the smallest growth rates have the highest ages at maturity (Alm, 1959). These contradictory empirical findings indicate the need for further field experiments. 
Earlier theoretical studies have focused on other proximate mechanisms that can result in resource limitation. Hayes and Taylor (1990) used a life-history model to assess variations in optimal reproductive strategies of yellow perch in response to changes in mortality rates and diet composition. They showed that fish of larger size were expected when maturity was delayed or when fish or benthos were added to the diet. Also Heath and Roff (1996) studied a case where stunting was assumed to result from a low availability of one or more types of prey items. Using an allocation model based on ontogenetic shifts in the diet of yellow perch populations, they demonstrated that growth curves predicted for reduced benthic rations matched observations on stunted yellow perch population from Lac Hertel in Québec. In a corresponding empirical analysis, they could show that all stunted species in Lac Hertel fed on benthos while all non-stunted ones did not feed on benthos, except for white sucker. After reducing the abundance of white suckers in a lake in Michigan, Hayes and Taylor (1992) observed a diet shift of yellow perch from zooplankton to benthos, resulting in increased growth of yellow perch. This effect, however, was relatively small in magnitude and also did not occur immediately. Using an energy-budget model of northern pike, Diana (1987) demonstrated that competition, lack of appropriately sized prey, and extremely warm conditions may reduce pike growth. These four studies underscore that stunting can also be caused by resource limitation in the form of lack of certain prey items.

Jennings et al. (1997) suggested that selective exploitation of large bluegill males may decrease the age and size of male maturation. In contrast, however, numerical simulations by Beard et al. (1997) showed that low angling mortalities for large bluegill males did not lead to delayed maturation but only to size distributions that were shifted toward larger fish.

In general, the optimal reaction norm for age and size at maturity depends both on growth conditions and on mortality rates. Experiments conducted by Alm (1959) provide empirical evidence for dome-shaped reaction norms for age and size at maturation: size at maturity is smaller in fast- and slow-growing fishes than in individuals with intermediate growth rates. Using computer simulations, Perrin and Rubin (1990) have shown that dome-shaped reaction norms are optimal when a finite life span and a negative correlation between reproduction and survival rates are assumed. In our study, dome-shaped reaction norms are observed under conditions of increased juvenile and adult survival. In other cases, the norm of reaction for size at maturity turned out to be monotonically increasing with age.

Evidently, effects of adaptations in the age at maturity on the length of individual fish and on the total biomass of populations are complex. Although the changes in age at maturity predicted for different proximate causes of stunting are relatively similar, the impacts on the characteristics of a fish population (e.g., length or total biomass) may be very different. Adaptive 
responses to the majority of proximate causes of stunting studied in this paper change the length of fish and their biomass only slightly. Exceptions are adaptive changes that are expected to result from increased fishing pressures: here, predictions differ markedly depending on whether or not adaptive responses are taken into account. Adaptive changes give rise to stunted growth, whereas a mere consideration of ecological factors would lead us to expect normal-sized fish. This example illustrates that taking into account ecological factors only, while disregarding their adaptive consequences, may result in qualitatively misleading predictions.

\section{Acknowledgements}

The authors wish to thank Tim Benton, David Claessen, Olav Rune Godø, Veijo Kaitala, Neil Metcalfe and Derek Roff for valuable comments on the manuscript. Financial support by the Finnish Committee for IIASA, the Adaptive Dynamics Network at IIASA, and by the Finnish Cultural Foundation is gratefully acknowledged. This study is part of the research project "Modeling and risk analysis of small and endangered populations" funded by the Academy of Finland.

\section{References}

Alm, G. (1959) Connection between maturity, size and age in fishes. Rep. Inst. Freshwat. Res. Drottningholm 40, 5-145.

Amundsen, P.-A. (1988) Effects of an intensive fishing programme on age structure, growth and parasite infection of stunted whitefish (Coregonus lavaretus L. s.1.) in Lake Stuorajavri, northern Norway. Finn. Fish. Res. 9, 425-434.

Beard Jr., T.D., Drake, M.T., Breck, J.E. and Nate, N.A. (1997) Effects of simulated angling regulations on stunting in bluegill populations. N. Amer. J. Fish. Manage. 17, 525-532.

Beverton, R.J.H. and Holt, S.J. (1957) On the Dynamics of Exploited Fish Populations. Fisheries Investment Series 2, Vol. 19, UK Ministry of Agriculture and Fisheries, London.

Bodaly, R.A., Vuorinen, J. and Macins, V. (1991) Sympatric presence of dwarf and normal forms of the lake whitefish, Coregonus clupeaformis, in Como Lake, Ontario. Can. Field-Nat. 105, $87-90$.

Burrough, R.J. and Kennedy, C.R. (1979) The occurrence and natural alleviation of stunting in a population of roach, Rutilus rutilus (L.). J. Fish Biol. 15, 93-109.

Campbell, E.A. (1998) Predation by small walleyes on yellow perch: effects of prey size distribution. Trans. Amer. Fish. Soc. 127, 588-597.

Craig, J.F., Kipling, C., Le Cren, E.D. and McCormack, J.C. (1979) Estimates of the numbers, biomass and year-class strengths of perch (Perca fluviatilis L.) in Windermere from 1967 to 1977 and some comparisons with earlier years. J. Anim. Ecol. 48, 315-325.

Deelder, C.L. (1951) A contribution to the knowledge of the stunted growth of perch (Perca fluviatilis L.) in Holland. Hydrobiologia 3, 357-378.

Diana, J.S. (1987) Simulation of mechanisms causing stunting in northern pike populations. Trans. Amer. Fish. Soc. 116, 612-617. 
Eschmeyer, R.W. (1937) Some characteristics of a population of stunted perch. Pap. Mich. Acad. Sci. Arts Lett. 23, 611-631.

Geritz, S.A.H., Kisdi, É., Meszéna, G. and Metz, J.A.J. (1998) Evolutionarily singular strategies and the adaptive growth and branching of the evolutionary tree. Evol. Ecol. 12, 35-57.

Grimaldi, J. and Leduc, G. (1973) The growth of the yellow perch in various Quebec waters. Nat. Can. 100, 165-176.

Hayes, D.B. and Taylor, W.W. (1990) Reproductive strategy in yellow perch (Perca flavescens): Effects of diet ontogeny, mortality, and survival costs. Can. J. Fish. Aquat. Sci. 47, 921-927.

Hayes, D.B. and Taylor, W.W. (1992) Response of yellow perch and the benthic invertebrate community to a reduction in the abundance of white suckers. Trans. Amer. Fish. Soc 121, 36-53.

Heath, D. and Roff, D.A. (1987) Test of genetic differentiation in growth of stunted and nonstunted populations of yellow perch and pumpkinseed. Trans. Amer. Fish. Soc. 116, 98-102.

Heath, D. and Roff, D.A. (1996) The role of trophic bottlenecks in stunting: a field test of an allocation model of growth and reproduction in yellow perch, Perca flavescens. Environ. Biol. Fishes 45, 53-63.

Heino, M. and Kaitala, V. (1997) Evolutionary consequences of density dependence on optimal maturity in animals with indeterminate growth. J. Biol. Systems 5, 181-190.

Hutchings, J.A. (1993) Adaptive life histories effected by age-specific survival and growth rate. Ecology 74, 673-684.

Jennings, M.J., Claussen, J.E. and Philipp, D.P. (1997) Effect of population size structure on reproductive investment of male bluegill. N. Amer. J. Fish. Manag. 17, 516-524.

Koli, L. (1990) Suomen Kalat. Porvoo: Werner Söderström Osakeyhtiö.

Leggett, W.C. and Power, G. (1969) Differences between two populations of landlocked Atlantic salmon (Salmo salar) in Newfoundland. J. Fish. Res. Bd. Can. 26, 1585-1596.

Linfield, R.S.J. (1980) Ecological changes in a lake fishery and their effects on a stunted roach Rutilus rutilus population. J. Fish Biol. 16, 123-144.

Linløkken, A. and Seeland, P.A.H. (1996) Growth and production of perch (Perca fluviatilis L.) responding to biomass removal. Ann. Zool. Fennici 33, 427-435.

Metz, J.A.J., Mylius, S.D. and Diekmann, O. (1996) When does evolution optimise? On the relation between types of density dependence and evolutionarily stable life history parameters. WP-96-04 IIASA.

Nibbelink, N.P. and Carpenter, S.R. (1998) Interlake variation in growth and size structure of bluegill (Lepomis macrochirus): inverse analysis of an individual-based model. Can. J. Fish. Aquat. Sci. 55, 387-396.

Nyberg, P. (1976) Production and food consumption of perch in two Swedish forest lakes. Scripta Limnol. Ups. 421, Klotenprojektet Rap. 6, 1-97.

Parker, H.H. and Johnson, L. (1991) Population structure, ecological segregation and reproduction in non-anadromous Arctic charr, Salvelinus alpinus (L), in four unexploited lakes in the Canadian high Arctic. J. Fish Biol. 38, 123-147.

Perrin, N. and Rubin, J.F. (1990) On dome-shaped norms of reaction for size-to-age at maturity in fishes. Funct. Ecol. 4, 53-57.

Post, J.R. and McQueen, D.J. (1994) Variability in first-year growth of yellow perch (Perca flavescens): predictions from a simple model, observations, and an experiment. Can. J. Fish. Aquat. Sci. 51, 2501-2512.

Rask, M. (1983) Differences in growth of perch (Perca fluviatilis L.) in two small forest lakes. Hydrobiologia 101, 139-144.

Rask, M. (1992) Changes in the density, population structure, growth and reproduction of perch, Perca fluviatilis L. in two acidic forest lakes in southern Finland. Environ. Pollut. 78, 121-125.

Reimers, N. (1979) A history of a stunted brook trout population in an alpine lake: a life span of 24 years. Calif. Fish and Game 65, 195-215.

Reznick, D.A., Bryga, H. and Endler, J.A. (1990) Experimentally induced life-history evolution in a natural population. Nature 346, 357-359.

Ridgway, L.L. and Chapleau, F. (1994) Study of a stunted population of yellow perch (Perca flavescens) in a monospecific lake in Gatineau Park, Quebec. Can. J. Zool. 72, 1576-1582. 
Ricker, W.E. (1975) Computation and interpretation of biological statistics of fish populations. Fisheries Research Board of Canada, Bulletin No. 191.

Roff, D.A. (1983) An allocation model of growth and reproduction in fish. Can. J. Fish. Aquat. Sci. 40, 1395-1404.

Roff, D.A. (1986) Predicting body size with life history models. BioScience 36, 316-323.

Roff, D.A. (1992) The Evolution of Life Histories. Theory and Analysis. Chapman \& Hall, New York.

Sandheinrich, M.B. and Hubert, W.A. (1984) Intraspecific resource partitioning by yellow perch, Perca flavescens, in a stratified lake. Can. J. Fish. Aquat. Sci. 41, 1745-1752.

Szalai, A.J. and Dick, T.A. (1991) Role of predation and parasitism in growth and mortality of yellow perch in Dauplin Lake, Manitoba. Trans. Amer. Fish. Soc. 120, 739-751.

Tesch, F.-W. (1955) Das Wachstum des Barsches (Perca fluviatilis L.) in verschiedenen Gewässern. Z. Fisch. 4, 321-420.

Treasurer, J.W. (1981) Some aspects of the reproductive biology of perch Perca fluviatilis L. Fecundity, maturation and spawning behaviour. J. Fish Biol. 18, 729-740.

Viljanen, M. and Holopainen, I.J. (1982) Population density of perch (Perca fluviatilis L.) at egg, larval and adult stages in the dys-oligotrophic Lake Suomunjärvi, Finland. Ann. Zool. Fennici 19, $39-46$.

Zeh, M., Ritter, E. and Ribi, G. (1989) Spawning and egg development of Perca fluviatilis in Lake Zürich. Aquat. Sci. 51, 100-107. 